\title{
High probability \\ ventilation-perfusion scan in primary pulmonary hypertension
}

\author{
SAT SHARMA MD FRCPC, WILLIAM D LESLIE MD FRCPC, MORLEY LERTZMAN MD FRCPC \\ Sections of Respiratory and Nuclear Medicine, Department of Medicine, \\ University of Manitoba, Winnipeg, Manitoba
}

\begin{abstract}
S Sharma, WD Leslie, M LertzMan. High probability ventilation-perfusion scan in primary pulmonary hypertension. Can Respir J 1995;2(3):179-182.

The perfusion lung scan is a valuable noninvasive tool in the evaluation of patients with pulmonary arterial hypertension of undetermined cause and for the exclusion of occult largevessel pulmonary thromboembolism. Peripheral patchy defects have been reported in primary pulmonary hypertension (PPH) but there are no well documented reports of segmental or larger perfusion defects. A case of a 55-yearold male witl severe pulmonary hypertension of unknown etiology who had persistent high probability perfusion scan patterns over a period of two years is reported. No evidence of thromboembolism was present on pulmonary angiography. A discussion of the case and a review of the literature on the role of lung scan in PPH are presented. Most patients with PPH have normal or low probability perfusion scans; ligh probability scans occur rarely.
\end{abstract}

Key Words: Perfision lung scun. Primary pulmonary hypertension

\section{Scintigraphie de perfusion et de ventilation à haute probabilité dans l'hypertension pulmon- aire primitive}

RÉSUMÉ : La scintigraphie pulmonaire de perfusion est unc étude précieuse sans effraction tissulaire qui permet d'évaluer les patients souffrant d'hypertension artérielle pulmonaire d'origine indéterminée et d'exclure une thromboembolie occulte d'un gros vaisseau pulmonaire. Un deficit de perfusion parcellaire et périphérique a été observé dans l'hypertension pulmonaire primitive (HPP) mais il n'y a pas de rapports bien documentés sur un déficit de perfusion segmentaire ou plus étendu. On rapporte le cas d'un homme de 55 ans souffrant d'une hypertension pulmonaire grave d'étiologie inconnue chez qui pendant plus de deux ans les scintigraphies de perfusion se sont constamment révélées à haute probabilité pour une thromboembolie. L'angiographie pulmonaire n'avait révélé aucune thromboembolie. On présente une discussion de ce cas ainsi qu'une revue de la littérature sur le rôle de la scintigraphie pulmonaire dans I'HPP. La plupart des patients souffrant d'HPP présentent des scintigraphies de perfusion normales: ou il liable probabilité; les scintigraphies à haute probabilité sont rares.
$\mathrm{E}$ XTENSIVE EXPERIENCE OI: VARIOUS AUTHORS INDICATES that the perfusion lung scan is an excellent noninvasive tool for distinguishing between pulmonary hypertension due to large-vessel chronic thronboembolism and pulmonary hypertension of undetemined cause (1-4). The pattern of abnormality seen in puimonary hypertension of undetermined caluse due to thrombotic ocelusion of microvascula- ture. or primary pulmonaty hypertension ( $\mathrm{PPH})$, consists of diffuse patchy peripheral defects. Perfusion defects of a lohar or segmental nature have not been well documented in PPH. The present case is reported to demensirate that multiple segmental defects typical of pulmonary cmboli may be present in a patient with nonthrombocmbolic pulnonary hypertension. 


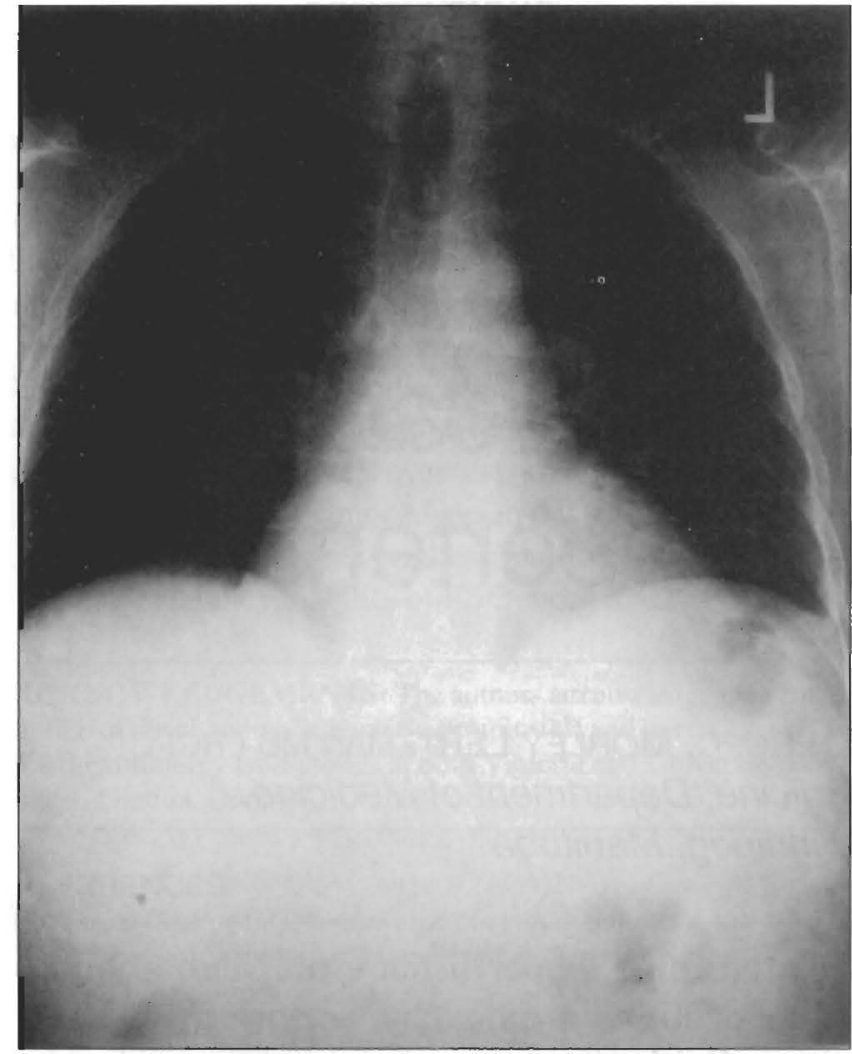

Figure 1) Posteroanterior chest radiograph showing mild cardiomegaly and prominence of the proximal pulmonary arteries. The lang parenchyma is normal

\section{CASE PRESENTATION}

A 55-year-old Caucasian male with a 10 pack-year smohing history presented with gradually progressive exertional dyspnea and a single episode of exertional syncope. He had a past history of systemic hypertension and a long history of Raynaud's phenomenon. Physical examination revealed elevated venous pressure, right ventricular lift, right ventricular fourth heart sound and at systolic murmur of tricuspid regurgitation over the right sternal border. Electrocardiography showed typical findings of right ventricular hypertrophy. A chest radiograph showed cardiomegaly and large pulmonary arteries (Figure 1). Transthoracic echocardiogram revealed normal left ventricle size and function, and a markedly dilated right ventricle with a severe reduction in right ventricular systolic function. Severe tricuspid regurgitation was present and paradoxic motion of interventricular septum was seen. Pulmonary artery systolic pressure was estimated by transvalvular flow velocity to be in excess of $90 \mathrm{mmHg}$. A six-view technetium-99m macroaggregated albumin perfusion lung scan showed multiple, hilateral, triangular wedgeshaped segmental and subsegmental defects (Figure 2). ${ }^{1.33}$ Xenon ventilation scan showed mild asymmetry but no segmental ventilatory abnormalities, and therefore established the presence of multiple areas of ventilation-perfusion mismatch (Figure 2, bottom). Subsequent ventilation perfusion scans done at an interval of one weck and one month were unchanged from the first study. No evidence of deep
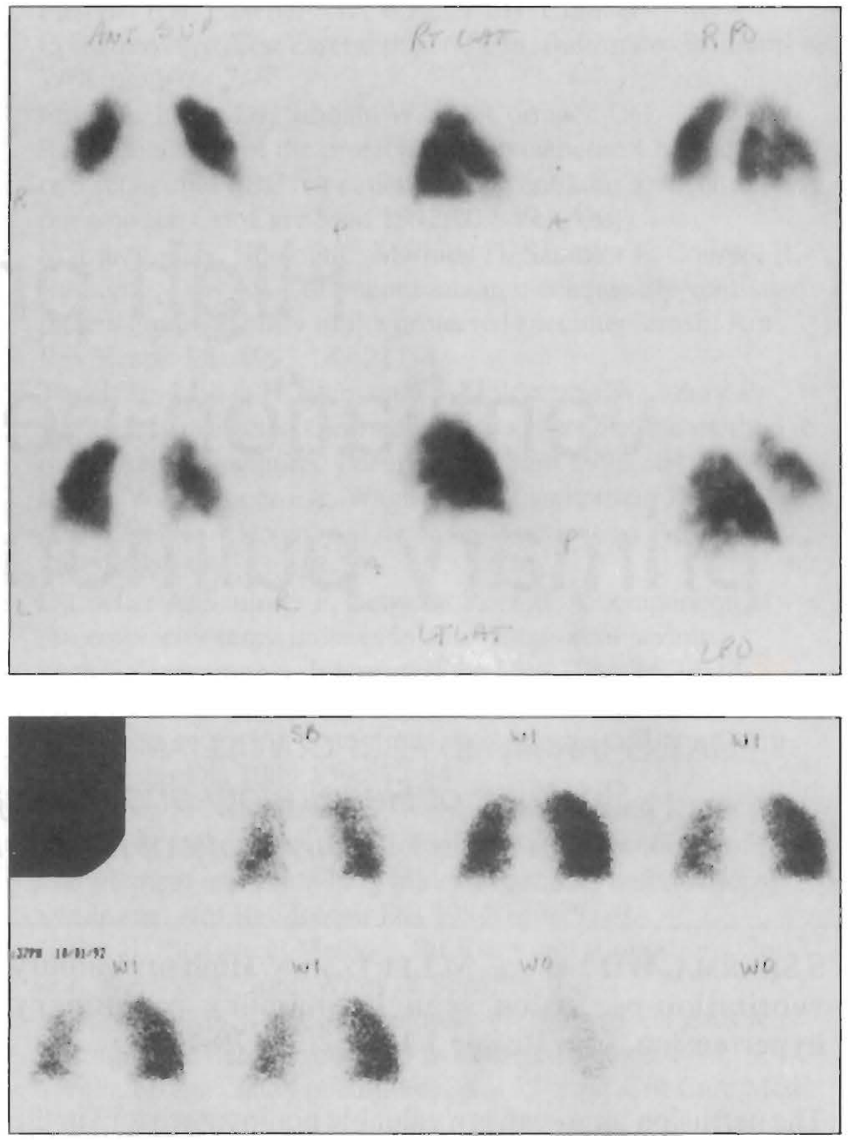

Figure 2) Top Perfusion lung scanning was performed with tirthnetium-99m macroaggregated albumin. Images were obtained in six projections: anterior (ANT SUP, upper left), right lateral ( $R T$ $L A T$, upper centre), right posterior oblique (RPO, upper right). posterior (POST SUP, lower left), left lateral (LT LAT, lower centre) and left posterior oblique (LPO, lower right). The initial study showed a large right upper lobe defect that involves more than a segment. Segmental defects are also present in the right middle lobe, lingula and anteromedial basal segment left lower lobe. Bottom ${ }^{133}$ Xenon ventilation scan in the posterior view shows only mild asymmetry but no segmental abnormalities. SB Single breath; WI Wash-in phase; WO Wash-out phase

venous thrombosis in the lower extremities was lound on venography. Pulmonary function studies were consistent with a moderate restrictive pattern: forced vital capacity (FVC) $1.92 \mathrm{~L} \mathrm{(58 \%} \mathrm{predicted);} \mathrm{forced} \mathrm{expiratory} \mathrm{volume} \mathrm{in}$ $1 \mathrm{~s}\left(\mathrm{FEV}_{1}\right) 1.51 \mathrm{~L} / \mathrm{s}$ (56\% predicted); $\mathrm{FEV}_{\mathrm{l}}: \mathrm{FVC}$ ratio $78 \%$; total lung capacity $61 \%$ predicted; and carbon monoxide diffusing capacity of the lung $19.4 \mathrm{~mL} / \mathrm{min} / \mathrm{mmHg}(80 \%$ predicted). Arterial blood gases showed pH 7.42, $\mathrm{PaCO}_{2}$ $32 \mathrm{mmHg}, \mathrm{PaO}_{2} 71 \mathrm{mmHg}$ and bicarbonate $21 \mathrm{mmol} / \mathrm{L}$. No mediastinal or parenchymal abnormalities were identified on an uninfused computed tomography (CT) scan of the chest. Pulmonary artery angiography was not performed. The patient was initially treated with intravenous heparin followed by adequate long term anticoagulation with oral warfarin therapy

The patient returned two ycars later with increasing dyspnea and worsening right-sided heart failure. Medications included lisinopril, furosemide, ranitidine and warfarin. 


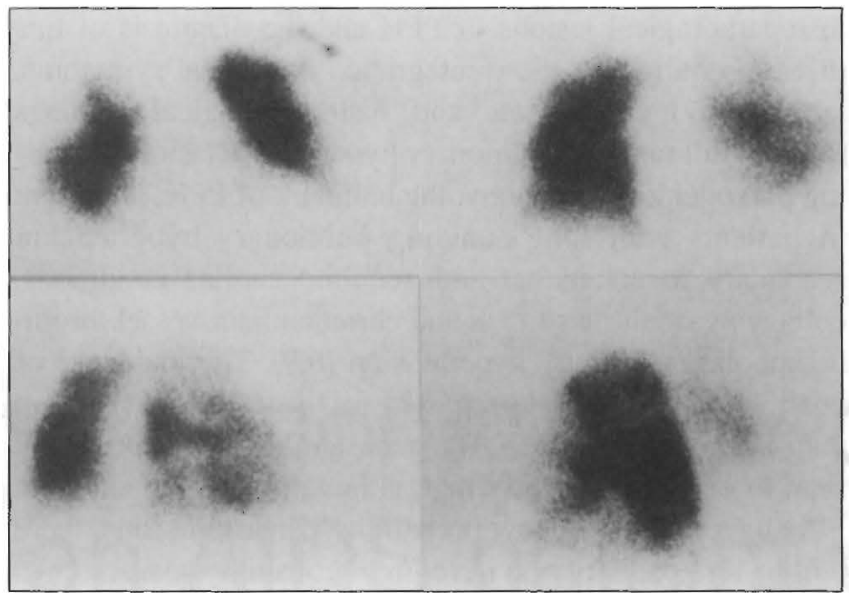

Figure 3) The perfusion scan was repeated two years after the first examination. Projections are anterior (upper lefi), posterior (upper right), right posterior oblique (lower left) and right posterior oblique (lower right). Previously described defects are more extensive and there are new defects in the right posterior lung base. Perfusion abnormalities are periph'tal and wedge-shaped, and they appear to conform to segmental and lobar boundaries. Simultuneous assessment of regional ventilation on a technetium- $99 \mathrm{~m}$ diethylenetriamine pentaacetic acid (DTPA) radiencrosol scan H'as normal (not shown)

Complete blood cell count, elcetrolyles, blood urea nitrogen, creatinine and creatine kinase were within normal ranges. Chest radiograph, electrocardiograph, pulmonary function studies and echocardiographic findings were unchanged. A perfusion scan showed multiple segmental perfusion defects in both lungs, with further deterioration in the right lung compared with the previous scans (Figure 3 ). The ventilation scan, performed with tcchnetium-99m diethylenetriamine pentaacetic acid (DTPA) radioaerosol, was normal. Pulmonary artery angiography and hemodynamic measurement showed mean pulmonary artery pressure of $50 \mathrm{mmHg}$. Review of the study by two independent radiologists failed to reveal any evidence of proximal or distal vessel thromboembolic disease (Figure 4). No evidence of organized old thrombi such as arterial wall irregularity, web formation or narrowing of vessels was noted. Additional studies performed at this time showed positive serum antinuclear antibodies (ANA) in a titre of more than $1: 10,000$ dilutions. Erythrocyte sedimentation rate, DNA, extractable nuclear antigens and anticentromere antibodies were all negative. Positive ANA may indicate a disease process such as progressive systemic sclerosis or CREST (calcinosis cutis, Raynitud's phenomenon, esophageal motility disorder, sclerodactyly and telangiectasia) syndrome, but no clinical or laboratory evidence of an underlying collagen vascular disease was found. A repeat CT scan of the chest failed to show any mediastinal or parenchymal abnormalities.

\section{DISCUSSION}

This is a well documented case of a false positive perfusion lung scan in a patient with severe pulmonary artery hypertension of undetermined origin. Our patient has either PPH or pulmonary arterial hypertension associated with col
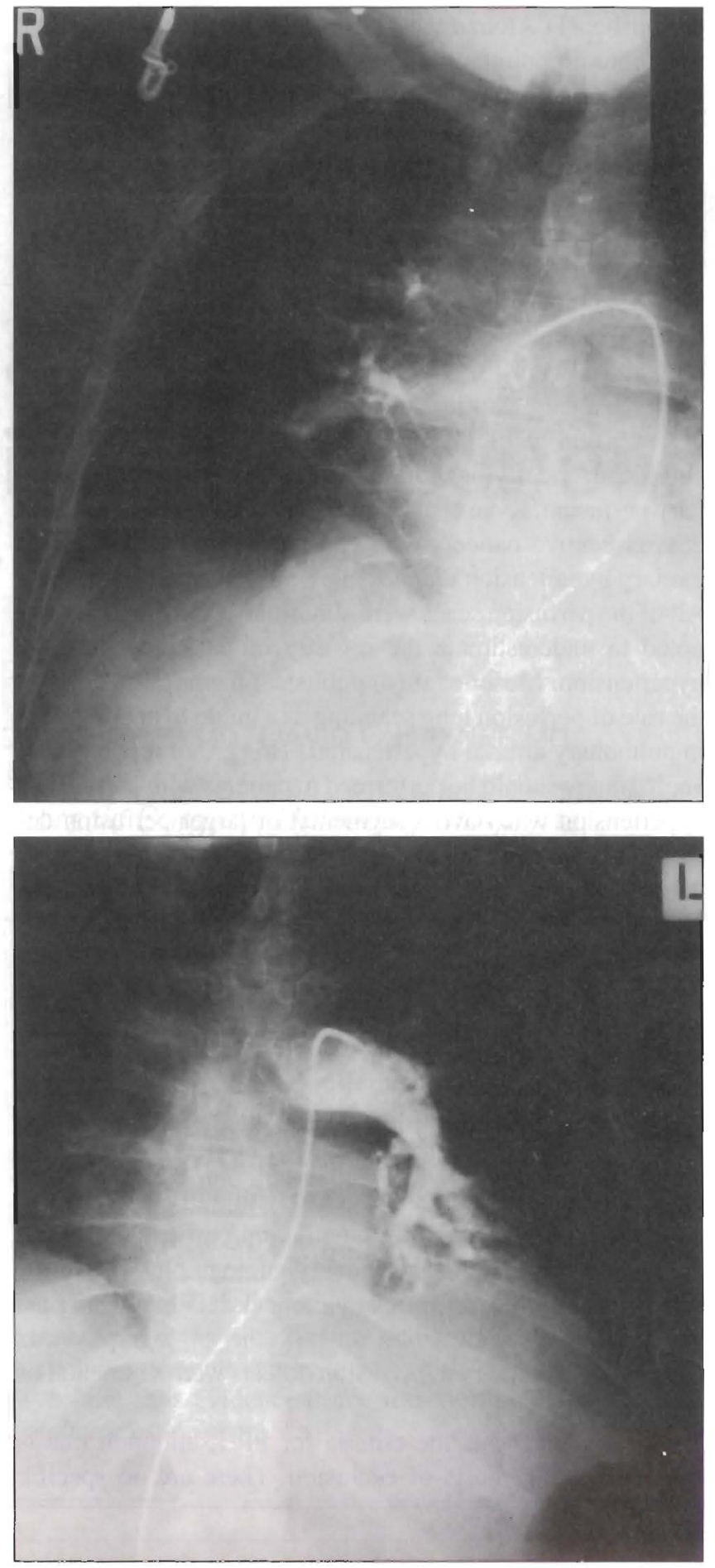

Figure 4) Bilateral pulmonary angiography shows dilated proximal pulmonary arteries and a mean arterial pressure of $50 \mathrm{mmHg}$. There was no evidence of recent or chronic thromboemboli. Top Right sicle; Bottom Left side

lagen vascular disease limited to the pulmonary vasculature. The clinical picture and pulmonary angiogram are consistent with PPH. Perfusion lung scans are used as a guide to further evaluation of patients with pulmonary hypertension who maly have chronic large vessel thromboembolism amenable to thromboendarterectomy. The value of the perfusion scan as at screening investigation before angiography has been firmly 
established. D'Alonzo et al (1) reported a series of 25 patients with chronic pulmonary hypertension. All eight patients in whom thromboembolic disease was established on subsequent angiography had high probability scans, whereas scans were normal or low probability in patients with PPH. Powe et al (2) reviewed their experience with 58 patients who were evaluated for pulmonary arterial hypertension. Thirtyfour patients had a definitive diagnosis made by open lung biopsy, angiography and/or autopsy. All eight patients with thromboembolism had high probability scans. None of the 13 patients with PPH had a high probability scan. Three of the 13 patients who had nonembolic secondary pulmonary hypertension had high probability scans, but they also had significant underlying thoracic disease known to alter pulmonary perfusion. Ryan et al (3) reviewed the perfusion scans in 25 consecutive patients with chronic thromboembolic pulmonary hypertension diagnosed on pulmonary angiography. All of the perfusion scans were abnormal, although they were noted to underestimate the severity of pulmonary arterial hypertension. Moser et al (4) published the largest series on the role of perfusion lung scanning as a guide to angiography in pulmonary arterial hypertension. This group reported that angiography should be performed in patients with pulmonary hypertension who have a segmental or larger perfusion defect. Their series included 64 patients with PPH and 46 patients with chronic thromboembolic pulmonary hypertension. On evaluating the perfusion lung scans of these 110 patients, no segmental defects were noted on the scans of 64 patients with PPH, whereas all 46 patients with thromboembolic hypertension had one or more defects that were segmental or larger in size.

Recently one other case of a scan-angiographic disparity was reported in which a false positive perfusion scan occurred in a patient with PPH. Worsley et al (5) retrospectively studied the records of 35 patients with PPH. One of the patients had high probability ventilation-perfusion scan but no thromboembolism on pulmonary angiography. However, this report does not include any clinical details of this case and there is no information on how the angiography was reviewed or whether the perfusion defects were segmental or persistent.

Our patient meets the criteria for PPH, although this is essentially a diagnosis of exclusion. There are no specific histopathological lesions of PPH and the diagnosis of this disease requires the close integration of clinical symptoms, laboratory investigations and histopathological findings $(6,7)$. A full range of pulmonary hypertensive lesions including plexogenic arteriopathy, the hallmark of PPH, is present in patients with long standing pulmonary hypertension secondary to congenital and acquired cardiac conditions, collagen vascular disorders and chronic major vessel thromboembolic pulmonary hypertension $(8,9)$. The incidence of positive ANA has been reported in 14 to $29 \%$ of cases in various registries $(10,11)$. The persistently positive perfusion scan in our patient shows that, although most patients with PPH have normal or low probability perfusion scans, there will be rare patients who have high probability scans.

\section{REFERENCES}

1. D'Alonzo GE, Bower JS, Dantzker DR. Differentiation of patients with primary and thromboembolic pulmonary hypertension. Chest 1984;85;457-61.

2. Powe JE, Paleveski HI, McCarthy KE, Alavi A. Pulnoniry arterial hypertension: value of perfusion scintigraphy. Radiology 1987; 164:727-30.

3. Ryan KL, Fedullo PF, Davis GB, Vasquez TE, Moser KM Perfusion scan findings underestimate the severity of angiographic and hemodynamic compromise in chronic thromboembolic pulmonary hypertension. Chest 1988;93:1180-5.

4. Moser KM, Page GT, Ashburn WL, et al. Perfusion lung scans provide a guide to which patients with apparent primary pulmonary hypertension merit angiography. West J Med 1988; [48:167-70.

5. Worsely DF, Palevsky HI, Alavi A. Ventilation-perfusion Lung scanning in the evaluation of pulmonary hypertension. I Nucl Med 1994;35:793-6.

6. Rubin LJ. Primary pulmonary hypertension: ACCP consensus statement. Chest 1993;104:236-50.

7. Rich S. Primary pulmonary hypertension. Prog Cardiovasc Dis [9)88:31:205-38.

8. Young RH, Mark GJ. Pulmonary vascular changes in scleroderma. Am J Med 1978;64:998-1004.

9. Moser KM, Bloor CM. Pulmonary vascular lesions occurring In patients with chronic major vessel thromboembolic pulmonary hypertension. Chest 1993;103:685-9.

10. Heath DE, Edwards JE. The pathology of hypertensive pulmonary disease. A description of six grades of structural changes in the pulmonary arteries with special reference to congenital cardiac septal defects. Circulation 1958; 18:533-47.

11. Dantzker DR. Primary pulmonary hypertension. The American experience. Chest 1994;105:26s-8s. 


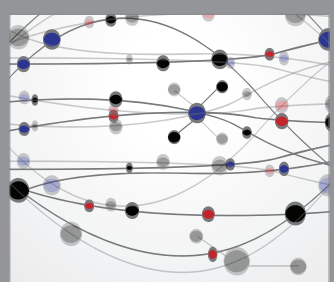

The Scientific World Journal
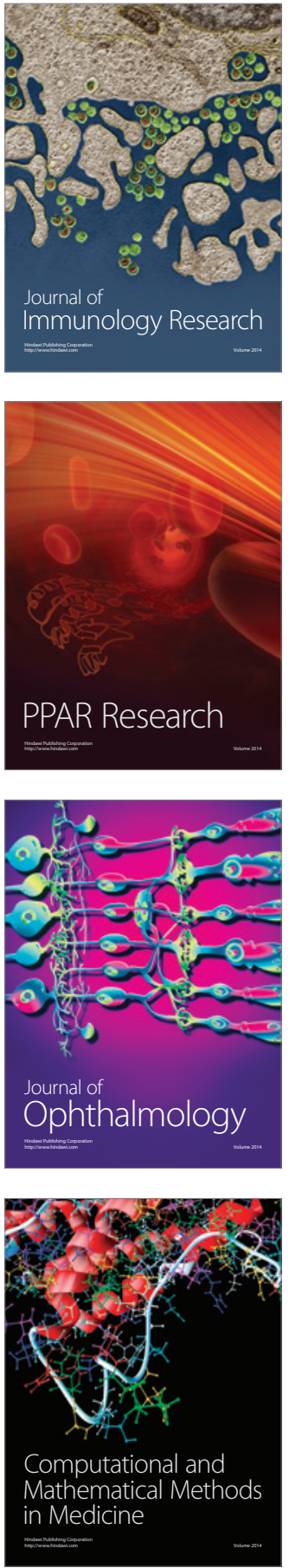

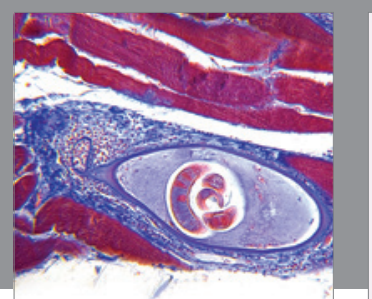

Gastroenterology Research and Practice

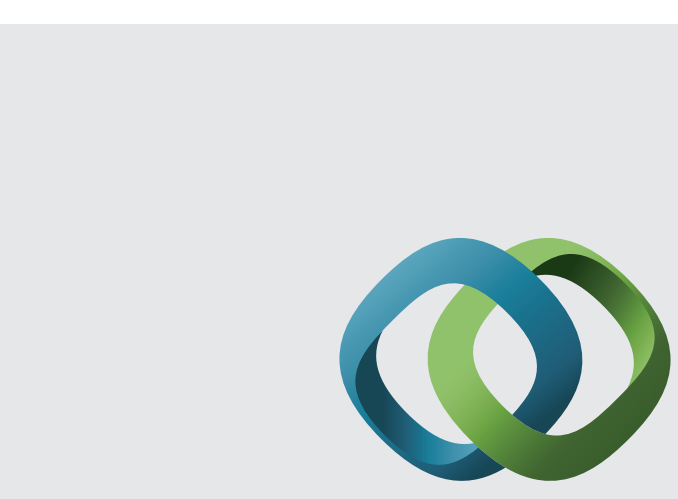

\section{Hindawi}

Submit your manuscripts at

http://www.hindawi.com
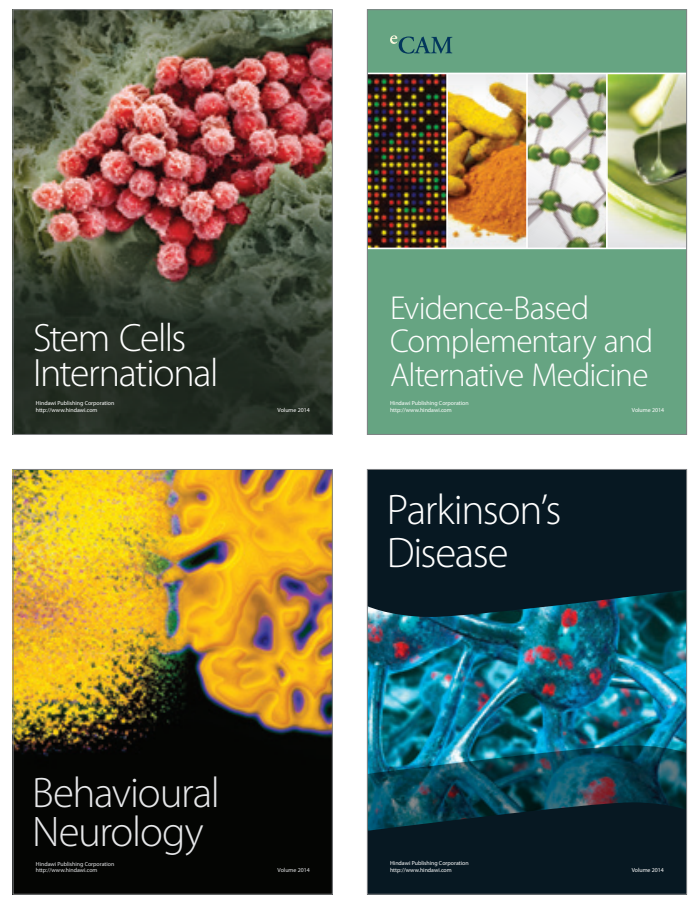
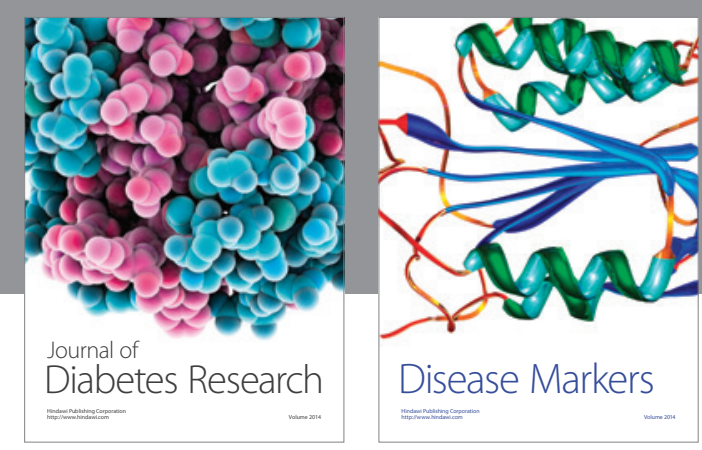

Disease Markers
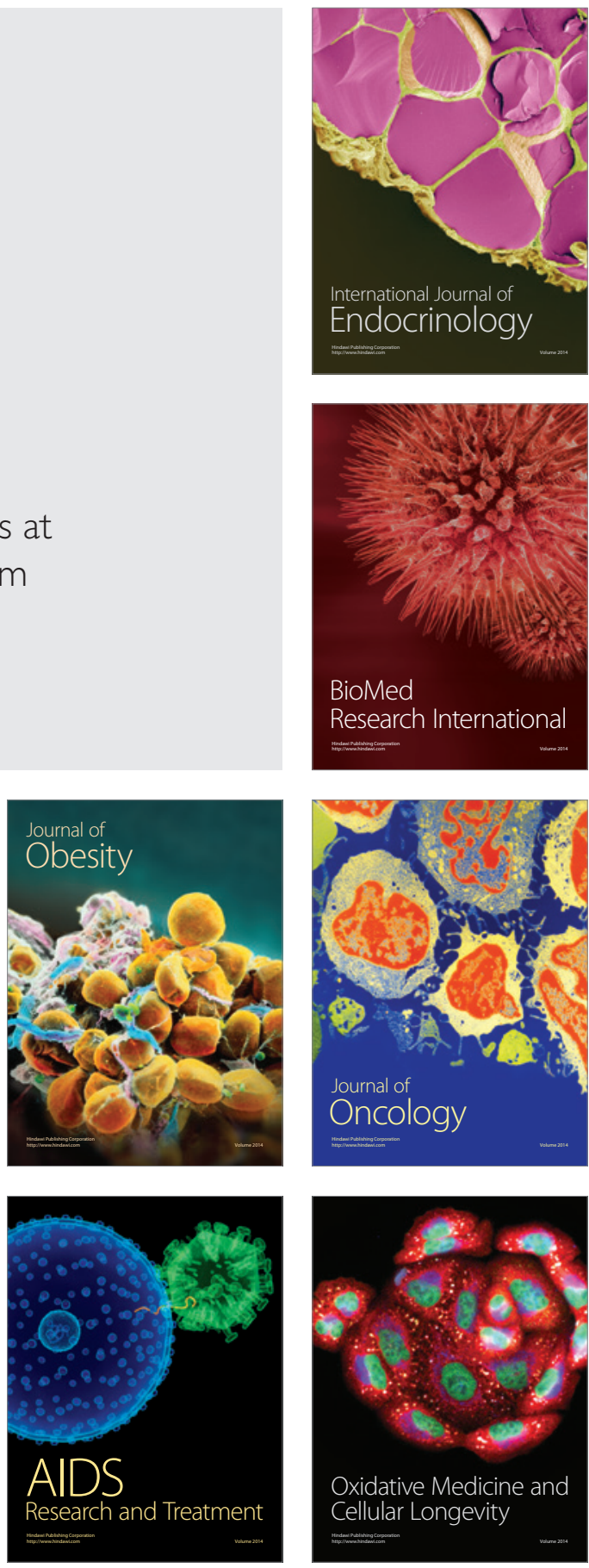